\title{
Artificial neural networks and multiple linear regression model using principal components to estimate rainfall over South America
}

\author{
T. Soares dos Santos ${ }^{1}$, D. Mendes ${ }^{1}$, and R. Rodrigues Torres ${ }^{2}$ \\ ${ }^{1}$ Federal University of Rio Grande do Norte, Campus Universitário Lagoa Nova, Natal, RN, 59078-970, Brazil \\ ${ }^{2}$ Federal University of Itajubá, Instituto de Recursos Naturais, Av. BPS, 1303, Pinheirinho, Itajubá, MG, 37500-903, Brazil
}

Correspondence to: T. Soares dos Santos (tthalysoares@gmail.com)

Received: 2 June 2015 - Published in Nonlin. Processes Geophys. Discuss.: 6 August 2015

Revised: 1 January 2016 - Accepted: 7 January 2016 - Published: 27 January 2016

\begin{abstract}
Several studies have been devoted to dynamic and statistical downscaling for analysis of both climate variability and climate change. This paper introduces an application of artificial neural networks (ANNs) and multiple linear regression (MLR) by principal components to estimate rainfall in South America. This method is proposed for downscaling monthly precipitation time series over South America for three regions: the Amazon; northeastern Brazil; and the La Plata Basin, which is one of the regions of the planet that will be most affected by the climate change projected for the end of the 21st century. The downscaling models were developed and validated using CMIP5 model output and observed monthly precipitation. We used general circulation model $(\mathrm{GCM})$ experiments for the 20th century (RCP historical; 1970-1999) and two scenarios (RCP 2.6 and 8.5; 2070-2100). The model test results indicate that the ANNs significantly outperform the MLR downscaling of monthly precipitation variability.
\end{abstract}

\section{Introduction}

The forecasting of meteorological phenomena is a complex task. The mathematical, statistical, and dynamic methods developed in recent decades help address the problem, but there is still a need to investigate new techniques to improve the results. One of these techniques is statistical downscaling, which involves the reduction of the model's spatial scale. Downscaling techniques can be divided into two broad categories: dynamic and statistical. Dynamic techniques focus on numerical models with more detailed resolution, while statistical (or empirical) techniques use transfer functions between scales. Currently, numerical weather prediction (NWP) models can forecast various meteorological variables with acceptable accuracy (Ramírez et al., 2006).

Specifically, rainfall is of great interest, both for its climatic and meteorological relevance and for its direct effect on agricultural output, hydropower generation, and other important economic factors. However, it is one of the most difficult variables to forecast, because of its inherent spatial and temporal variability (Wilson and Vallée, 2002; Antolik, 2000). For this reason, the temporal and spatial scales involved are not yet solved satisfactorily by the available numerical models (Olson et al., 1995).

Ramos (2000), studying artificial neural networks (ANNs) and multiple linear regression (MLR), found that the neural-network method performed better than the linearregression method, although both showed good performance for monthly and seasonal rainfall. Ramírez et al. (2005), using observed daily rainfall in the São Paulo region, found that ANNs outperformed MLR, which showed a high bias for days without rain. Ramírez et al. (2006) analyzed daily rainfall in southeastern Brazil and concluded that the ANN method tended to predict moderate rainfall with greater accuracy during austral summer compared to ETA model forecasts. Mendes and Marengo (2010) reported that the daily rainfall in the Amazon Basin is better represented by ANNs than autocorrelation models.

In this context, the aim of this study is to conduct a statistical downscaling to estimate rainfall over South America (SA), based on some models used in the fifth report of the 
Table 1. List of models from the CMIP5 data set used in this study.

\begin{tabular}{lll}
\hline Acronym & Model & Resolutions \\
\hline ACCESS & ACCESS1.0 & $1.3^{\circ} \times 1.9^{\circ}$ \\
CCSM & CCSM4 & $0.9^{\circ} \times 1.3^{\circ}$ \\
CNRM & CNRM-CM5 & $1.4^{\circ} \times 1.4^{\circ}$ \\
CSIRO & CSIRO-Mk3-6-0 & $1.9^{\circ} \times 1.9^{\circ}$ \\
EC-EARTH & EC-EARTH & $1.1^{\circ} \times 1.1^{\circ}$ \\
HadGEM-ES & HadGEM2-ES & $1.3^{\circ} \times 1.9^{\circ}$ \\
INM & INMCM4 & $1.5^{\circ} \times 2.0^{\circ}$ \\
MPI & MPI-ESM-LR & $1.9^{\circ} \times 1.9^{\circ}$ \\
MRI & MRI-CGCM3 & $1.1^{\circ} \times 1.1^{\circ}$ \\
NorESM & NorESM1-M & $1.9^{\circ} \times 2.5^{\circ}$ \\
\hline
\end{tabular}

IPCC (Intergovernmental Panel on Climate Change), by applying artificial neural networks and multiple linear regression using principal components.

\section{Data and methods}

\subsection{Data}

We used monthly precipitation simulations for the austral summer (December-January-February) and winter (JuneJuly-August) generated by 10 models (Table 1) from the CMIP5 project (Coupled Model Intercomparison Project 5th Phase), obtained from the Earth System Grid Federation (ESGF) of the German Climate Computing Center (http://ipcc-ar5.dkrz.de) and the Program for Climate Model Diagnosis and Intercomparison (http://pcmdi3.1lnl.gov). All model simulations for the 20th century were compared with the precipitation data of the CRU TS 3.0 (Mitchell and Jones, 2005), produced by the Climatic Research Unit (CRU) - University of East Anglia (UEA). These data cover the period from 1901 to 2005 and have spatial resolution of $0.5^{\circ} \times 0.5^{\circ}$. We used climate simulations for the 20th century (historical) in the 1970-1999 period and projections for the 21st century (Representative Concentration Pathways - RCP 2.6 and 8.5) for the period 2070-2099, as defined by Moss et al. (2010).

Our focus on South America is because it is one of the planet's regions that will be most affected by the climate change projected for the end of the 21st century (Marengo et al., 2010). According to Magrin et al. (2014), significant trends in precipitation and temperature have been observed in SA. In addition, changes in climate variability and in extreme events have severely affected the region. The three subregions evaluated in South America were defined according to the precipitation regime: the Amazon (AMZ), northeastern Brazil (NEB), and the La Plata Basin (LPB) (Fig. 1).

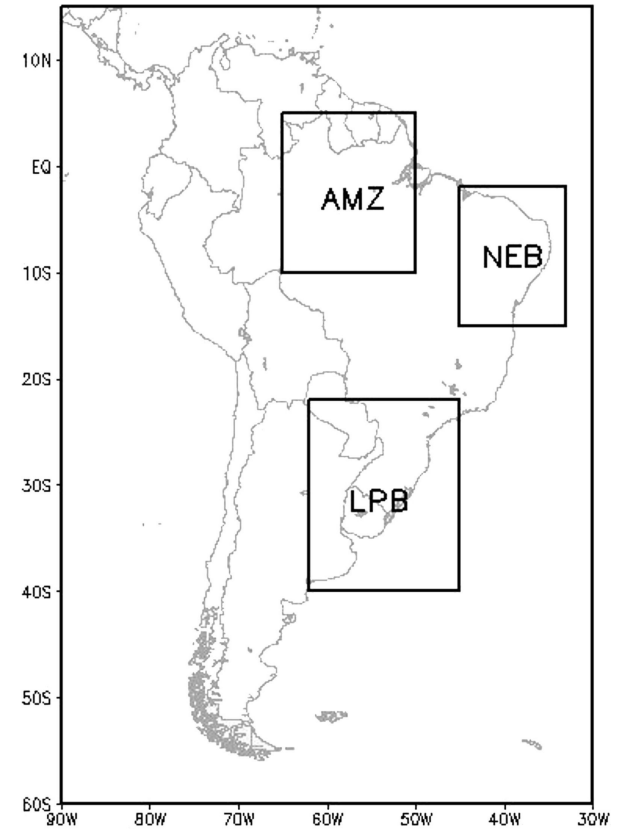

Figure 1. Illustration of the study areas of the defined regions.

\subsection{Methods}

\subsubsection{Artificial neural networks}

An ANN is a system inspired by the operation of biological neurons with the purpose of learning a certain system. The construction of an ANN is achieved by providing a stimulus to the neuronal model, calculating the output, and adjusting the weights until the desired output is achieved. An entry is submitted to the ANN along with a desired target, a defined response for the output (when this is the case, the training is regarded as supervised). An error field is built based on the difference between the desired response and the output of the system. The error information is used as feedback for the system, which adjusts its parameters in a systematic way; in other words, the backpropagation error algorithm is used to train the network. According to Alsmadi et al. (2009) the backpropagation architecture is the most popular, most effective, and easiest-to-learn model for complex, multilayered networks. This network is used more than all others combined. This algorithm has a first phase with a functional propagation signal (feedforward) and a second phase with the backpropagation of the error (backpropagation).

In the first phase, the functional signal based on the inputs propagates through the network until generating an output, with the weights of synapses remaining fixed. In the second phase, the output is compared with a target, producing an error signal. The error signal propagates from the output to the input, and the weights are adjusted in such a way as to minimize the error. The process is repeated until the perfor- 


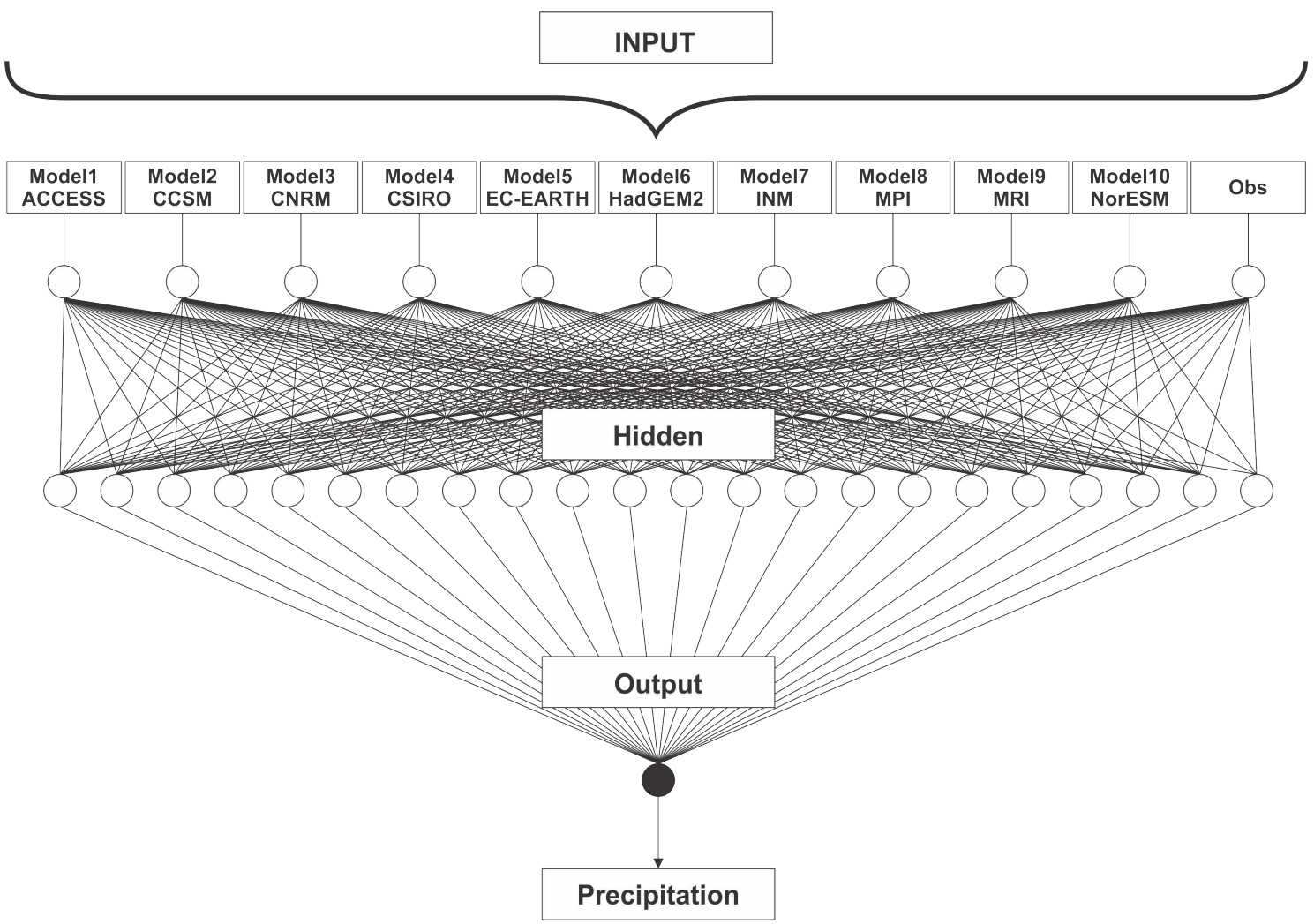

Figure 2. Structure of the artificial neural network.

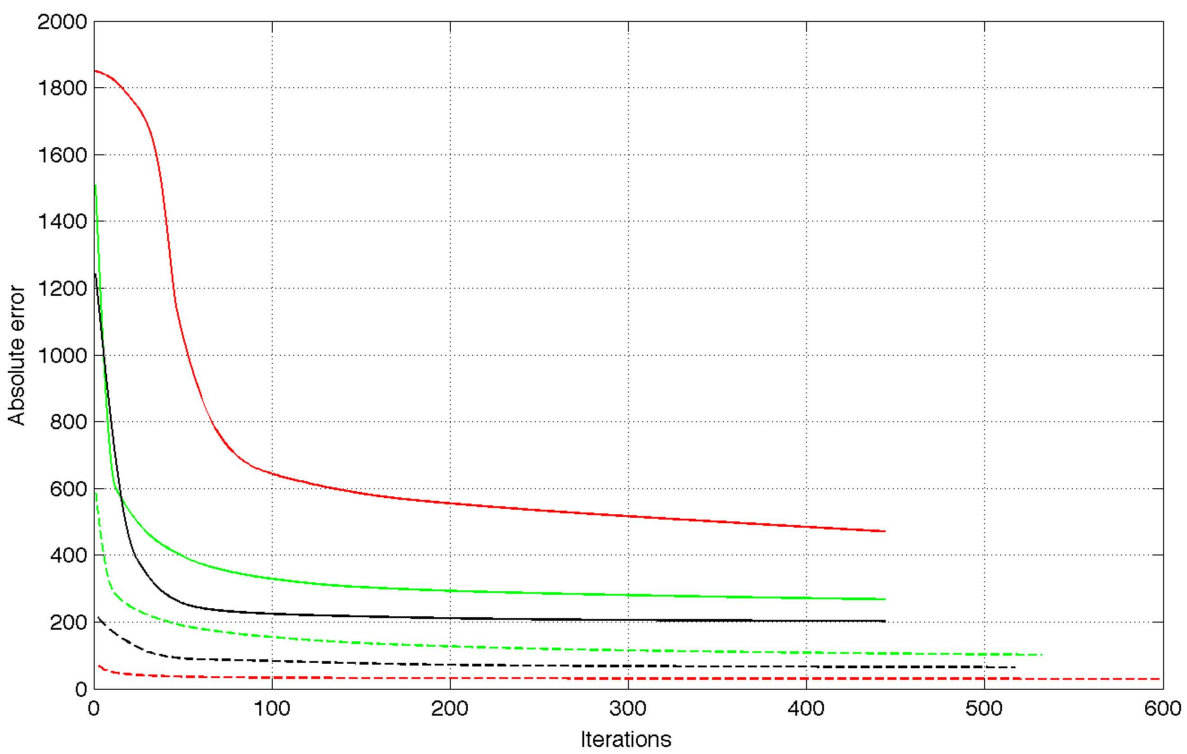

Figure 3. Absolute error as a function of the number of iterations; AMZ (green), NEB (red), and LPB (black). Continuous lines represent the summer period for each region, and the dashed lines represent winter.

mance is acceptable. As such, the performance of the ANN is strongly dependent on the data source.

The first part of the data is used for training, the second is used for cross-validation, and the third part is used for test- ing. The architecture of the ANN used in the present study can be found in Fig. 2. It consists of an input, a hidden layer, and an output layer. The number of intermediate units was obtained through trial and error. During the training, the per- 

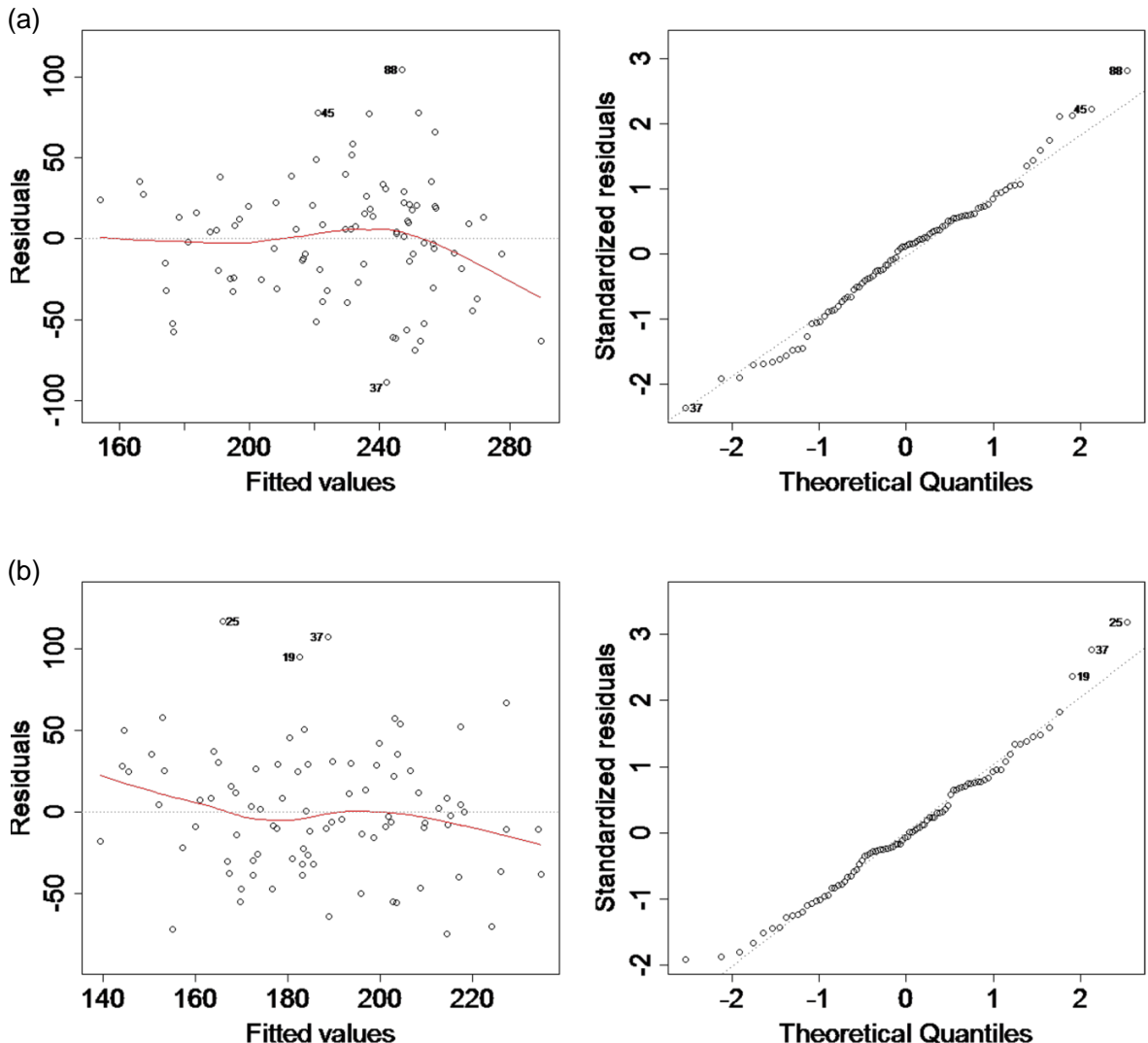

(c)
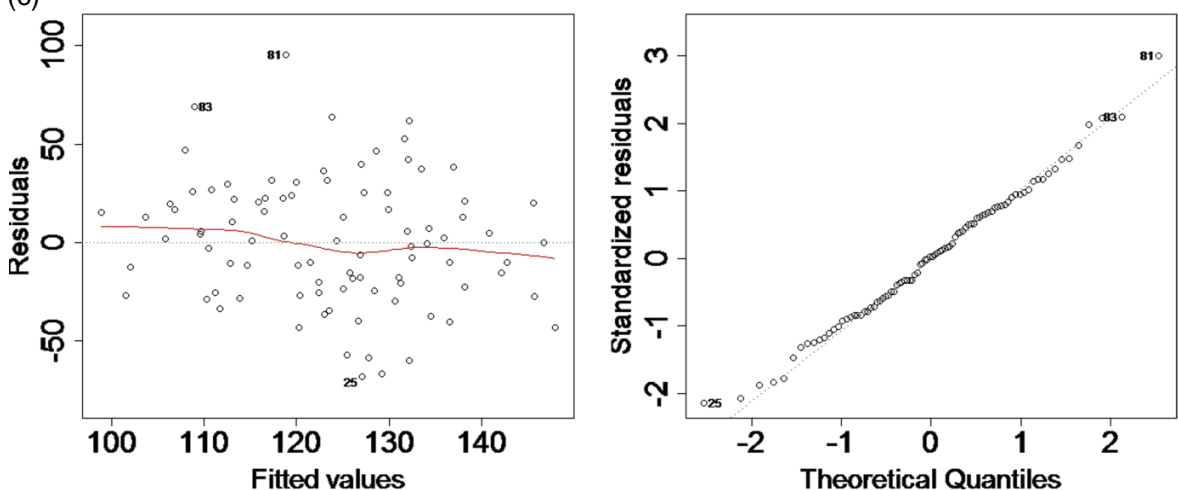

Figure 4. Residuals $\times$ fitted values and theoretical quantiles, for the summer. (a) AMZ, (b) NEB, and (c) LPB.

formance of the ANN is also assessed within the validation set.

The structure of the ANN used here involves training of 11 predictors (10 outputs of the models plus the observation data) as input to the network, and the best network performance is selected. We therefore expect that the ANN will be able to provide more reliable values (through the error analysis between the simulated values) than when using only climate models.

\subsubsection{Multiple linear regression using principal components}

MLR is a statistical technique that consists of finding a linear relationship between a dependent (observed) variable and more than one independent variable (outputs of the general circulation models (GCMs)). A multiple regression model can be represented by the following equation:

$Y_{i}=a+b_{1} X_{1}+b_{2} X_{2}+\cdots+b_{m} X_{m}+C$, 
Table 2. Proportion and cumulative proportion of variance for the indicated regions. Left column for summer, and right column for winter.

\begin{tabular}{|c|c|c|c|c|c|c|c|c|c|c|c|c|c|c|c|c|c|c|c|c|}
\hline \multirow{5}{*}{$\begin{array}{l}\text { Proportion } \\
\text { of variance } \\
\text { Cumulative } \\
\text { proportion }\end{array}$} & \multicolumn{10}{|c|}{ Summer } & \multicolumn{10}{|c|}{ Winter } \\
\hline & \multicolumn{10}{|c|}{$\mathrm{AMZ}$} & \multicolumn{10}{|c|}{ AMZ } \\
\hline & $\mathrm{PC} 1$ & $\mathrm{PC} 2$ & PC3 & $\mathrm{PC} 4$ & PC5 & PC6 & PC7 & PC8 & PC9 & PC10 & $\mathrm{PC} 1$ & $\mathrm{PC} 2$ & PC3 & $\mathrm{PC} 4$ & PC5 & PC6 & PC7 & PC8 & PC9 & PC10 \\
\hline & 0.24 & 0.12 & 0.13 & 0.11 & 0.09 & 0.08 & 0.11 & 0.06 & 0.06 & 0.04 & 0.71 & 0.07 & 0.05 & 0.04 & 0.03 & 0.03 & 0.02 & 0.02 & 0.02 & 0.01 \\
\hline & 0.24 & 0.36 & 0.49 & 0.60 & 0.69 & 0.77 & 0.84 & 0.90 & 0.96 & 1.00 & 0.71 & 0.78 & 0.83 & 0.87 & 0.90 & 0.93 & 0.95 & 0.97 & 0.99 & 1.00 \\
\hline & \multicolumn{10}{|c|}{ NEB } & \multicolumn{10}{|c|}{ NEB } \\
\hline Proportion & $\mathrm{PC} 1$ & $\mathrm{PC} 2$ & PC3 & PC4 & PC5 & PC6 & PC7 & PC8 & PC9 & PC10 & $\mathrm{PC} 1$ & $\mathrm{PC} 2$ & PC3 & PC4 & PC5 & PC6 & PC7 & PC8 & PC9 & PC10 \\
\hline of variance & 0.32 & 0.13 & 0.10 & 0.09 & 0.08 & 0.08 & 0.06 & 0.07 & 0.04 & 0.03 & 0.54 & 0.10 & 0.08 & 0.07 & 0.06 & 0.04 & 0.04 & 0.03 & 0.02 & 0.02 \\
\hline \multirow{2}{*}{$\begin{array}{l}\text { Cumulative } \\
\text { proportion }\end{array}$} & 0.32 & 0.45 & 0.55 & 0.64 & 0.72 & 0.80 & 0.86 & 0.93 & 0.97 & 1.00 & 0.54 & 0.64 & 0.72 & 0.79 & 0.85 & 0.89 & 0.93 & 0.96 & 0.98 & 1.00 \\
\hline & \multicolumn{10}{|c|}{ LPB } & \multicolumn{10}{|c|}{ LPB } \\
\hline Proportion & PC1 & $\mathrm{PC} 2$ & PC3 & PC4 & PC5 & PC6 & PC7 & PC8 & PC9 & $\mathrm{PC} 10$ & $\mathrm{PC} 1$ & $\mathrm{PC} 2$ & PC3 & PC4 & PC5 & PC6 & PC7 & PC8 & PC9 & PC10 \\
\hline of variance & 0.16 & 0.15 & 0.14 & 0.10 & 0.11 & 0.09 & 0.07 & 0.06 & 0.06 & 0.06 & 0.16 & 0.15 & 0.12 & 0.11 & 0.10 & 0.09 & 0.08 & 0.07 & 0.06 & 0.06 \\
\hline $\begin{array}{l}\text { Cumulative } \\
\text { proportion }\end{array}$ & 0.16 & 0.31 & 0.45 & 0.55 & 0.66 & 0.75 & 0.82 & 0.88 & 0.94 & 1.00 & 0.16 & 0.31 & 0.43 & 0.54 & 0.64 & 0.73 & 0.81 & 0.88 & 0.94 & 1.00 \\
\hline
\end{tabular}

where $Y_{i}$ is the dependent variable; $X_{1}, X_{2}, \ldots, X_{m}$ are the independent variables; $a$ is the intercept; $b_{1}, b_{2}$, and $b_{m}$ are the multiple regression coefficients, to be estimated by the least-squares method (Wilks, 1995); and $C$ is the error term.

In spite of their obvious success in many applications, MLRs present multicollinearity when employed with climatic variables. In this regard, the parameter estimation errors can be incorrectly interpreted (Leahy, 2000). To resolve this problem, we used principal components (PCs). This method seeks to reduce the number of variables through orthogonal transformations and to remove the multicollinearity of the independent variables. The PCs of the explanatory variables are therefore a new set of variables with the same information as the original variables, but uncorrelated.

MLR is commonly used in various research areas and is widely accepted by the scientific community. The ANNs are still being inserted in science, especially when it comes to climate studies. Our intention is to show advantages of using ANNs for the weather. The advantages of the ANNs stand out: the nonlinearity inherent networks that allow this technique can perform functions that a linear program (such as MLR) can not. In addition, a neural network can be designed to provide information not only about which particular pattern, but also on the confidence in the decision.

\section{Results and discussion}

\subsection{Validation of the ANNs}

After using the precipitation simulations for the period 19701999 with the ANNs, we obtained a final error after a number of interactions, which ranged from 1 to 600 (Fig. 3). One of the difficulties of using ANNs involves identifying the best stopping point for training (Haykin, 2001), because the training error starts out with a maximum value, decreases rapidly, and then levels off, indicating there is no more error to cor- rect. In the summer, the network became stable more rapidly, indicating that the GCMs employed converge to the same pattern of precipitation.

With respect to winter, the networks remained unstable for a longer time before finding the minimum error. The NEB region should be highlighted, which required the largest number of iterations, around 600 . This is possibly related to the greater variability of rainfall in this season (Fig. 3).

According to Villanueva (2011), it is assumed that the three sets (training, validation, and testing) contain independent samples and that they are well capable of representing the problem being addressed. One should therefore expect that good performance of the validation set will imply good performance of the testing set. In this study, the validation values were closest to the test values in summer.

\subsection{Validation of the MLR by PCs}

To validate the MLR, the following assumptions need to be met: (i) the residuals must have random distribution around mean zero (homoscedasticity); (ii) the residuals should have a normal distribution; and (iii) variance must be homogeneous (da Silva and Silva, 2014).

Figures 4 and 5 show that the residuals versus adjusted values meet the assumption of homoscedasticity. With respect to the $Q-Q$ plot, the quantiles of the residuals versus the normal distribution indicate that all regions present normality in the residuals. Given that, the closer the residuals are to the line, the closer they are to having normal distribution. The employed data therefore fit the MLR by the PC model. Based on the PC analysis (Table 2), one can see that in summer for the $\mathrm{AMZ}$ region the accumulated proportion explains around $77 \%$ in NEB and $80 \%$ in PC6, while in winter the PC1 of the AMZ explained $71 \%$ and PC3 explained $72 \%$ in NEB, thus representing the greatest variability of precipitation in these regions. In general, one can observe that a smaller number of climate models were required in winter to capture the 

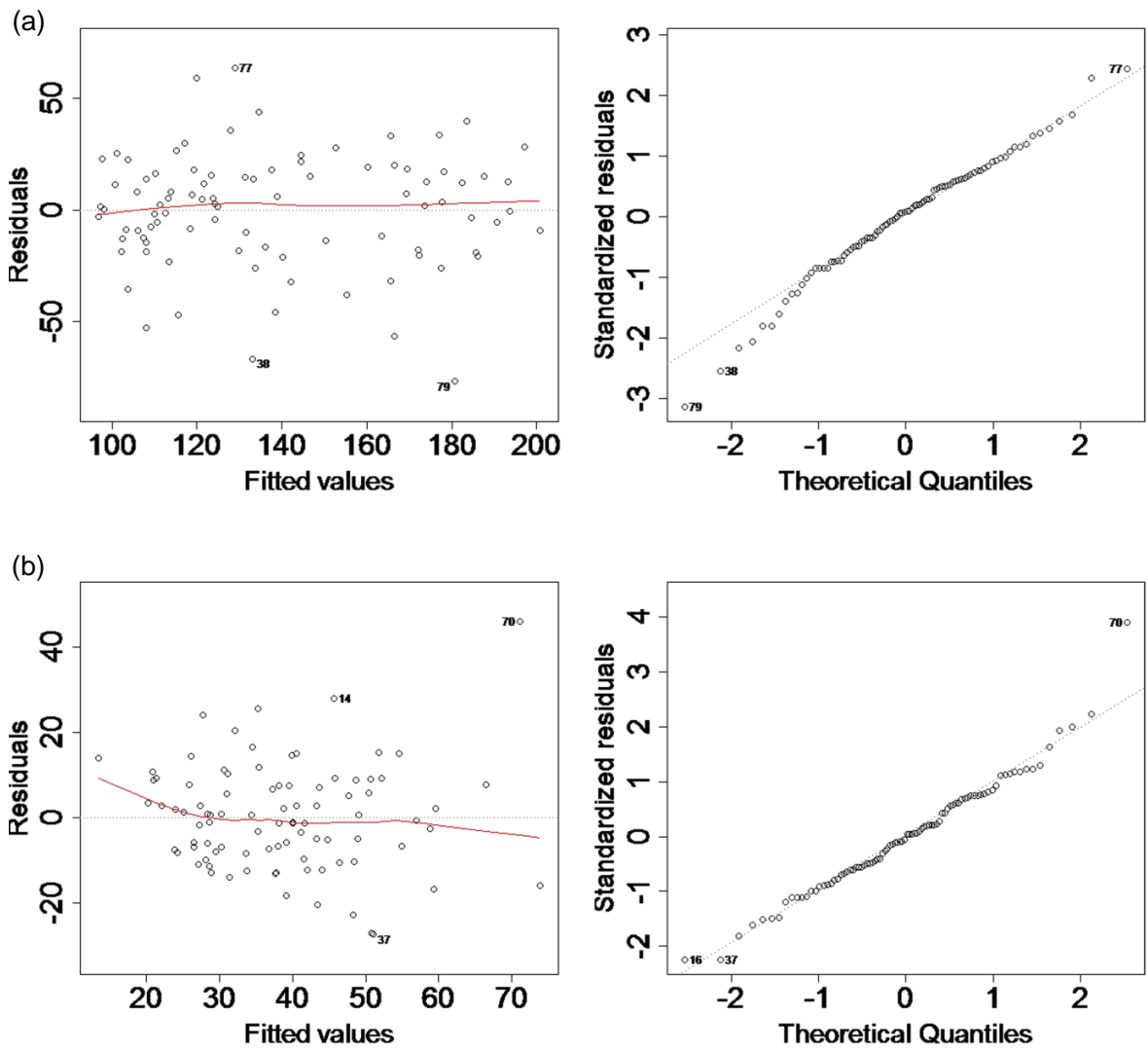

(c)
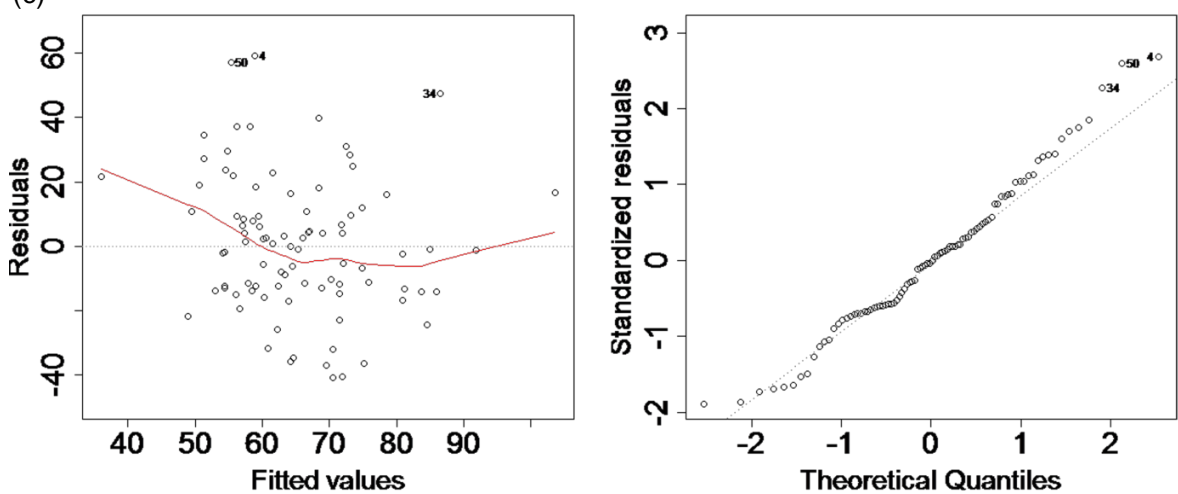

Figure 5. The same as in Fig. 4 but for winter.

variance of precipitation in these regions. Similar behavior of PCs in both seasons stands out in the LPB region, which may be due to the failure of GCMs to capture the variance of precipitation in this region.

Tables 3 and 4 show the Pearson's correlation coefficients at significance level of $5 \%$ between the ANNs and the observed data, and between the MLR by PCs and observed data, respectively. One can see that in both downscaling methods used the highest correlations occur in winter in all regions under study, indicating that the models are better able to represent the variability of precipitation during this season.
Ramírez et al. (2006) performed statistical downscaling for the precipitation forecast for the southeast of Brazil, using ANNs and MLR with the ETA model. The results suggested that the precipitation forecasts using ANNs performed better in winter than in summer, since the synoptic forcing is more pronounced and the deep convective activity is less common. One can also observe that in the regions NEB $($ ANN $\times$ Obs $)$ and LPB (MLR $\times$ Obs) the correlations of 38 and $20 \%$, respectively, were not statistically significant. The lowest correlation occurred in the LPB region. Seth et al. (2010) stated that the mean of the set of models reveals weaker moisture 
Table 3. $p$ value and Pearson's correlation coefficient at the level of significance of $5 \%$ between the ANNs and observed data from the CRU in all regions under study.

\begin{tabular}{lccc|ccc}
\hline & \multicolumn{3}{c}{$p$ value } & \multicolumn{3}{c}{ Correlation coefficient } \\
\cline { 2 - 7 } & AMZ & NEB & LPB & AMZ & NEB & LPB \\
\hline Summer & $1.60 \times 10^{-7 *}$ & 0.08 & $0.01^{*}$ & 0.61 & 0.38 & 0.18 \\
Winter & $5.28 \times 10^{-10 *}$ & $1.02 \times 10^{-10 *}$ & $1.20 \times 10^{-6 *}$ & 0.77 & 0.69 & 0.49 \\
\hline
\end{tabular}

* Significance $5 \%$.

Table 4. $p$ value and Pearson's correlation coefficient at the level of significance of $5 \%$ between the MLR by PCs and observed data from the CRU in all regions under study.

\begin{tabular}{lccc|ccc}
\hline & \multicolumn{3}{c}{$p$ value } & \multicolumn{3}{c}{ Correlation coefficient } \\
\cline { 2 - 7 } & \multirow{2}{*}{ AMZ } & NEB & LPB & AMZ & NEB & LPB \\
\hline Summer & $1.35 \times 10^{-10 *}$ & $2.69 \times 10^{-4 *}$ & 0.06 & 0.52 & 0.27 & 0.20 \\
Winter & $1.44 \times 10^{-18 *}$ & $9.56 \times 10^{-14 *}$ & $0.00^{*}$ & 0.62 & 0.60 & 0.33 \\
\hline
\end{tabular}

* Significance $5 \%$.

Table 5. Change in monthly precipitation in terms of an increase or decrease by the end of this century (2071-2100) in the scenarios RCP 8.5 and 2.6, in relation to the reference period 1971-1999 (observation), in millimeters per month and percentage.

\begin{tabular}{llrr|rr}
\hline & & \multicolumn{2}{c}{ RCP 8.5 } & \multicolumn{2}{c}{ RCP 2.6} \\
\cline { 3 - 6 } & & ANN $\left(\mathrm{mm}^{-1}\right)$ & MLR $\left(\mathrm{mm} \mathrm{\%}^{-1}\right)$ & ANN $\left(\mathrm{mm}^{-1}\right)$ & MLR (mm \%-1) \\
\hline \multirow{2}{*}{ AMZ } & Summer & $20.0 / 14.1$ & $23.1 / 16.5$ & $18.8 / 13.3$ & $22.4 / 15.8$ \\
& Winter & $-9.3 /-12.2$ & $-9.9 /-13.9$ & $-0.5 /-0.7$ & $-3.1 /-4.9$ \\
\hline \multirow{2}{*}{ NEB } & Summer & $55.2 / 36.2$ & $47.1 / 30.9$ & $48.0 / 33.1$ & $40.0 / 27.5$ \\
& Winter & $-6.6 /-42.7$ & $-6.9 /-44.5$ & $-1.81 /-9.41$ & $-2.06 /-10.7$ \\
\hline \multirow{2}{*}{ LPB } & Summer & $7.26 / 5.63$ & $5.7 / 4.42$ & $5.56 / 4.4$ & $4.01 / 3.15$ \\
& Winter & $-2.79 /-4.17$ & $-3.67 /-5.48$ & $-3.09 /-4.63$ & $-3.09 /-4.56$ \\
\hline
\end{tabular}

transport east of the Andes, which may be one of the factors that induce underestimation of precipitation in this region.

\subsection{Downscaling scenarios}

Table 5 presents the results of the monthly precipitation simulation for the end of this century (2071-2100) based on the 10 GCMs described previously in the RCP scenarios 8.5 and 2.6, in relation to the reference period 1971-1999 (observation) for the two downscaling methods.

In both scenarios, and employing both ANNs and MLR, an increase of precipitation in the summer and a decrease in the winter can be observed. These results corroborate the findings of Mendes and Marengo (2010), who used ANNs and autocorrelation to study changes in monthly precipitation for the Amazon Basin in scenarios A2, A1B, and B1, derived from five models of the CMIP3, used in the IPCC AR4. The authors found an increase in precipitation in the summer months and a reduction in winter.
In the NEB region (Table 5), an increase of precipitation in summer of around $30 \%$ was observed. With respect to winter, one can see a reduction of $40 \%$ in the higher-forcing scenario (RCP 8.5) and of $10 \%$ (RCP2.6) in the lower-climateforcing scenario. The IPCC AR4 revealed CMIP5 precipitation projections for the end of century (2081-2100) of increased precipitation from October to March over the southern part of southeastern Brazil and the La Plata Basin. From April to September, the CMIP5 ensemble projects precipitation increases over the La Plata Basin and northwestern SA near the coast (Stocker et al., 2013). According to Magrin et al. (2014) seasonal scales, rainfall reductions during winter and spring in southern Amazonia may indicate a late onset of the rainy season in those regions and a longer dry season. The changes are more intense for the late 21 st century and for the RCP8.5 when compared to scenario RCP 2.6, as can be seen in Table 5 . 


\section{Conclusions}

This paper investigated the applicability of artificial neural networks and multiple linear regression analysis by principal components, as temporal downscaling methods for the generation of monthly precipitation over South America (for current years and future scenarios). Both the ANN and MLR methods provided good fit with the observed data. This indicates that ANNs are a viable alternative for the modeling of precipitation in time series. ANNs can be compared with the statistical model, and this indicates that the networks are a potentially competitive tool.

The future scenarios used (RCP 2.6, lower climate forcing, and RCP 8.5, higher climate forcing) indicate an increase in precipitation in summer and a reduction in precipitation during winter according to both the methods used.

In general, the results showed that the use of ANNs produced more accurate results than MLR by PCs, which can be attributed to the fact that ANNs perform tasks that a linear program is unable to do. In addition, one of the advantages of ANNs is their capacity for temporal processing and thus their ability to incorporate not only concurrent but also several predictive values as inputs without any additional effort.

Acknowledgements. We are grateful to CAPES and PPGCC/UFRN for financial support.

Edited by: V. Perez-Munuzuri

Reviewed by: two anonymous referees

\section{References}

Alsmadi, M. K. S., Omar, K. B., and Noah, S. A: Back propagation algorithm: the best algorithm among the multi-layer perceptron algorithm, Int. J. Comput. Sci. Netw. Sec., 9, 378-383, 2009.

Antolik, M. S.: An overview of the National Weather Service's centralized statistical quantitative precipitation forecasts, J. Hydrol., 239, 306-337, doi:10.1016/S0022-1694(00)00361-9, 2000.

da Silva, A. G. and Silva, C. M. S.: Improving Regional Dynamic Downscaling with Multiple Linear Regression Model Using Components Principal Analysis: Precipitation over Amazon and Northeast Brazil, Adv. Meteorol., 2014, 928729, doi:10.1155/2014/928729, 2014.

Haykin, S. S.: Redes neurais, Bookman, Porto Alegre, 2001.

Leahy, K.: Multicollinearity: When the solution is the problem, in: Data mining cookbook: Modelling data for marketing, risk and costumer relationship management, edited by: Rud, O. P., John Wiley \& Sons, New York, 106-108, 2001.

Magrin, G. O., Marengo, J. A., Boulanger, J. P., Buckeridge, M. S., Castellanos, E., Poveda, G., Scarano, F. R. and Vicuna, S.: Central and South America, in: Climate Change 2014: Impacts, Adaptation, and Vulnerability. Part B: Regional Aspects. Contribution of Working Group II to the Fifth Assessment Report of the Intergovernmental Panel on Climate Change, Cambridge University Press, 1499-1566, 2014.
Marengo, J. A., Ambrizzi, T., Da Rocha, R. P., Alves, L. M., Cuadra, S. V., Valverde, M. C., Torres, R. R., Santos, D. C., and Ferraz, S. E.: Future change of climate in South America in the late twenty-first century: intercomparison of scenarios from three regional climate models, Clim. Dynam., 35, 1073-1097, doi:10.1007/s00382-009-0721-6, 2010.

Mendes, D. and Marengo, J. A.: Temporal downscaling: a comparison between artificial neural network and autocorrelation techniques over the Amazon Basin in present and future climate change scenarios, Theor. Appl. Climatol., 100, 413-421, doi:10.1007/s00704-009-0193-y, 2010.

Mitchell, T. D. and Jones, P. D. An improved method of constructing a database of monthly climate observations and associated high-resolution grids, Int. J. Climatol., 25, 693-712, doi:10.1002/joc.1181, 2005.

Moss, R. H., Edmonds, J. A., Hibbard, K. A., Manning, M. R., Rose, S. K., Van Vuuren, D. P., Carter, T. R., Emori, S., Kainuma, M., Kram, T., Meehl, G. A., Mitchell, J. F. B., Nakicenovic, N., Riahi, K., Smith, S. J., Stouffer, R. J., Thomson, A. M., Weyant, J. P., and Wilbanks, T. J.: The next generation of scenarios for climate change research and assessment, Nature, 463, 747-756, doi:10.1038/nature08823, 2010.

Olson, D. A., Junker, N. W., and Korty, B.: Evaluation of 33 years of quantitative precipitation forecasting at the NMC, Weather Forecast., 10, 498-511, doi:10.1175/15200434(1995)010<0498:EOYOQP>2.0.CO;2, 1995.

Ramírez, M. C. V., de Campos Velho, H. F., and Ferreira, N. J.: Artificial neural network technique for rainfall forecasting applied to the São Paulo region, J. Hydrol., 301, 146-162, doi:10.1016/j.jhydrol.2004.06.028, 2005.

Ramírez, M. C., Ferreira, N. J., and Velho, H. F. C.: Linear and nonlinear statistical downscaling for rainfall forecasting over southeastern Brazil, Weather Forecast., 21, 969-989, doi:10.1175/WAF981.1, 2006.

Ramos, A. M.: Desagregação espacial da precipitação simulada por modelos atmosféricos no Nordeste do Brasil, Master's thesis, Federal University of Paraíba, Paraíba, p. 96, 2000.

Seth, A., Rojas, M., and Rauscher, S. A.: CMIP3 projected changes in the annual cycle of the South American Monsoon, Climatic Change, 98, 331-357, doi:10.1007/s10584-009-9736-6, 2010.

Stocker, T. F., Qin, D., Plattner, G. K., Tignor, M., Allen, S. K., Boschung, J., Nauels, A., Xia, Y., Bex, V., and Midgley, P. M.: Climate change 2013: The physical science basis, Intergovernmental Panel on Climate Change, Working Group I Contribution to the IPCC Fifth Assessment Report (AR5), Cambridge University Press, New York, 2013.

Villanueva, W. J. P.: Síntese automática de redes neurais artificiais com conexões à frente arbitrárias, Master's thesis, Federal University of Campinas, Campinas, p. 220, 2011.

Wilks, D. S.: Statistical methods in the atmospheric sciences: An Introduction, Academic Press, San Diego, 1995.

Wilson, L. J. and Vallée, M.: The Canadian updateable model output statistics (UMOS) system: Design and development tests, Weather Forecast., 17, 206-222, doi:10.1175/15200434(2002)017<0206:TCUMOS>2.0.CO;2, 2002. 